\title{
Pedagogia social, vellesa i autonomia personal
}

\author{
Miquel Gómez Serra* \\ Núria Fabra Fres ${ }^{* *}$ \\ Carles Vila Mumbrú ${ }^{* * *}$
}

Resum

Els canvis demogràfics, socioculturals i econòmics transformen les relacions personals i socials, les estructures familiars i les formes tradicionals de tenir cura de les persones d'edat avançada, tant pel que fa a la promoció de la seva qualitat de vida com del manteniment de la seva autonomia personal. Aquests processos no només afecten els valors i els patrons de vida d'aquests individus, sinó també als seus cuidadors, que majoritàriament són familiars directes. La Pedagogia social té un paper en els diversos moments del cicle vital, i en l'etapa de la vellesa, aquest paper no sols es relaciona amb l'exercici dels professionals de l'acció socioeducativa, sinó també amb la vida i les necessitats de les pròpies persones ancianes i els seus cuidadors informals. Primer, per tal d'afavorir la qualitat de vida i l'autonomia de les persones ancianes; després, per prevenir o retardar la seva dependència; i, finalment, per acompanyar i tenir cura dels seus cuidadors.

\section{Paraules clau}

Vellesa, pedagogia social, qualitat de vida, benestar, autonomia personal, dependència.

\section{Introducció: I'univers de les persones d'edat avançada en l'Europa del segle XXI}

En la societat occidental contemporània han tingut i tenen lloc canvis de tipus demogràfic, sociocultural, econòmic i psicosocial que transformen les relacions personals i socials, així com les estructures familiars i, en conseqüència, les formes tradicionals d'atenció i cura de les persones d'edat avançada, tant pel que fa a la promoció de la seva qualitat de vida, com al manteniment de la seva autonomia personal i de la seva

$\left({ }^{*}\right) \quad$ Doctor en Pedagogia i professor titular del Departament de Teoria i Història de l'Educació (Universitat de Barcelona). Àrees d'investigació relacionades amb la Pedagogia social, els programes i serveis de benestar social i la planificació, gestió i avaluació de programes socioeducatius. Autor de diverses publicacions com Els serveis socials i la seva avaluació (2000), Evaluación de los servicios sociales (2004) o l'obra col-lectiva Participación infantil y construcción de la ciudadanía (2014). Forma part del Grup de Pedagogia Social (GPS) per a la Cohesió i la inclusió socials. Adreça electrònica: mgomez@ub.edu

$\left(^{* *}\right)$ Doctora en Pedagogia i professora associada del Departament de Teoria i Història de l'Educació (Universitat de Barcelona). Consultora i formadora. Coordinadora de la Taula de participació social del Departament de Justícia de la Generalitat de Catalunya. És autora de diverses publicacions com Guía de buenas prácticas en la atención psicoeducativa con niños y niñas víctimas de violencia (2010) o «Acompanyar y supervisar» en l'obra colllectiva Siete retos para la educación social (2013). Forma part del Grup de Pedagogia Social (GPS) per a la Cohesió i la inclusió socials. Adreça electrònica: nfabra@ub.edu

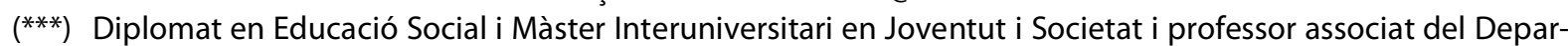
tament de Teoria i Història de l'Educació (Universitat de Barcelona). Tècnic de joventut i formador. Coordinador del projecte Be Youth Worker Today i del Cens de professionals en l'àmbit de la joventut de Catalunya (Associació Catalana de Professionals de les Polítiques de Joventut). Investigador del projecte HEBE i autor de publicacions sobre participació juvenil. Forma part del Grup de Pedagogia Social (GPS) per a la cohesió i inclusió socials. Adreça electrònica: carlesvilamumbru@ub.edu 
atenció i cura en el moment en què apareix o s'incrementa la seva situació de dependència.

En aquest sentit, no podem deixar de referir-nos al progressiu envelliment, així com també al sobreenvelliment, de la població europea occidental. Aquests processos s'han d'interpretar en clau positiva, ja que si bé és cert que comporten un increment de la presència de persones vulnerables o dependents $i$, per tant, de les necessitats socials i sanitàries associades, també signifiquen que els individus viuen un major nombre d'anys i, en la majoria dels casos i de les situacions, viuen millor i amb una qualitat de vida superior.

Així, les simulacions realitzades per l'Instituto Nacional de Estadística (INE) respecte a l'evolució de la població espanyola ${ }^{1}$ mostren el continuat procés d'envelliment a què s'enfronta la nostra estructura demogràfica, accelerat pel descens de la natalitat i els saldos migratoris negatius. S'ha de destacar que segons aquestes previsions els majors creixements de població es concentrarien en les edats avançades. Concretament, l'any 2052 el grup d'edat de majors de 64 anys s'incrementaria en 7,2 milions de persones (un $89 \%$ ) i passaria a constituir el $37 \%$ de la població total d'Espanya; per contra, aquest país perdria 9,9 milions de persones d'edats compreses entre els 16 i els 64 anys (un 32\%) i gairebé dos milions en el grup de població de 0 a 15 anys (un 26\%).

Vegem, a continuació, les previsions de l'INE respecte a l'evolució dels grups de població de majors de 64 anys en el període 2012-2052.

Taula 1. Evolució dels grups de població més gran de 64 anys de la població resident a Espanya per grups quinquennals a 1 de gener de 2012 i de 2052

\begin{tabular}{lcccc} 
Grups d'edat & 2012 & 2052 & Creixement absolut & Creixement relatiu (\%) \\
\hline 65 a 69 anys & 2.182 .424 & 2.596 .284 & 413.860 & 18,96 \\
70 a 74 anys & 1.737 .846 & 3.031 .001 & 1.293 .155 & 74,41 \\
75 a 79 anys & 1.700 .049 & 3.066 .833 & 1.366 .784 & 80,40 \\
80 a 84 anys & 1.300 .518 & 2.685 .942 & 1.385 .424 & 106,53 \\
85 a 89 anys & 749.481 & 2.079 .501 & 1.330 .020 & 177,46 \\
90 a 94 anys & 283.377 & 1.224 .782 & 941.405 & 332,21 \\
95 a 99 anys & 67.836 & 444.013 & 376.177 & 554,54 \\
100 i més anys & 8.143 & 75.494 & 67.351 & 827,10 \\
Total 64 i més anys & 8.029 .674 & 15.203 .850 & 7.174 .176 & 89,35 \\
\hline TOTAL Població & 46.192 .278 & 41.558 .096 & -4.634 .182 & $-10,03$ \\
\hline
\end{tabular}

Font: Instituto Nacional de Estadística (INE). Proyección de Población a Largo Plazo.

(1) Per a més informació, pot consultar-se la nota de premsa del 19 de novembre de 2012 de l'INE. Accés: http://www.ine.es/prensa/np744.pdf 
Les estimacions anteriors afecten de manera directa l'evolució de les taxes de dependència ${ }^{2}$, ja que si les tendències i comportaments demogràfics actuals es mantinguessin en un futur, l'any 2022 la taxa de dependència s'elevaria fins al 58\%. És a dir, per cada 10 persones en edat de treballar, I'any 2022 n'hi hauria a Espanya gairebé sis potencialment inactives (menors de 16 anys o majors de 64 anys).

Segons les previsions realitzades per l'INE, en 40 anys aquesta taxa de dependència s'elevaria gairebé al $100 \%$, el qual vol dir que, l'any 2052, per cada persona en edat de treballar pràcticament n'hi hauria una altra que no estaria en edat de fer-ho.

\section{Taula 2. Evolució de las taxes de dependència}

\begin{tabular}{cccc} 
Anys & Majors de 64 anys & Menors de 16 anys & Total (menors de 16 i majors de 64 anys) \\
\hline 2012 & 26,14 & 24,25 & 50,39 \\
2022 & 33,30 & 24,87 & 58,17 \\
2032 & 45,23 & 22,56 & 67,79 \\
2042 & 62,19 & 24,37 & 86,56 \\
2052 & 73,00 & 26,54 & 99,54 \\
\hline
\end{tabular}

Font: Instituto Nacional de Estadística (INE). Proyección de Población a Largo Plazo.

Així mateix, quan parlem de transformacions en les estructures familiars, no únicament hem de tenir en compte la pluralitat de models de convivència, sinó també els canvis interns que no afecten tant a les pròpies persones ancianes (majoritàriament famílies que s'ajusten al model tradicional) com als seus descendents. En aquest sentit, hem de destacar l'impacte que en els dispositius informals d'atenció i de cura de les persones grans ha tingut un procés històric de caràcter profundament democràtic i d'equitat social, com és la incorporació de la dona al treball remunerat fora de l'àmbit familiar.

Pensem que aquests processos de canvi són importants, no tant per com afecten els esquemes de valors i els patrons de vida de les persones ancianes actuals, sinó per com afectaran de manera directa als seus possibles cuidadors, que en la seva gran majoria són familiars directes. A més, hem de tenir en compte que quan la generació actualment adulta envelleixi, aquests canvis s'intensificaran, ja que els models de convivència familiar presentaran una major diversitat i les formes de solidaritat i d'ajuda mútua en el si de les famílies i dels dispositius informals d'atenció i de cura es veuran afectats per l'increment d'individus que han viscut sols, que han conegut separacions familiars, que han estat famílies reconstituïdes, sense fills o monoparentals, etc. Canvis, tots ells, que hem d'interpretar en clau positiva i com un indicador de la democratització i diversitat de la nostra societat. Però no per això podem obviar que fan necessari repensar i refor-

(2) La taxa de dependència dels més grans de 64 anys es defineix com el quocient entre la població major de 64 anys i la població major de 15 i menor de 65 anys, expressat en tant per cent. La taxa de dependència dels menors de 16 anys es defineix com el quocient entre la població menor de 16 anys i la població major de 15 i menor de 65 anys, expressat en tant per cent. La taxa de dependència de menors de 16 i majors de 64 anys es defineix com el quocient entre la població menor de 16 anys o major de 64 i la població major de 15 i menor de 65 anys, expressat en tant per cent. 
mular les polítiques socials d'atenció a les persones grans i, per tant, obliguen a repensar els dispositius d'atenció i de cura dels individus en situació de vulnerabilitat o de dependència ${ }^{3}$.

D'altra banda, a nivell prospectiu, s'han de tenir en compte no només els canvis demogràfics i en les estructures familiars, sinó també les transformacions internes de caràcter generacional i que es relacionen de forma directa amb aspectes socioculturals. Com molt bé escriuen els professors Fuentes i Solé (2012): «La generación del 68 que accede a la jubilación presenta como peculiaridad un nivel cultural y unos intereses sociales más amplios y la equiparación de mujeres y hombres respecto a los nuevos planes de jubilación al haber sido población activa. Esta nueva situación invita a cuestionar algunos de los referentes socioculturales de nuestra sociedad, en especial, la percepción del grupo de personas mayores como un colectivo prácticamente improductivo y marginal» (p. 85).

\section{La Pedagogia social i la cura de les persones d'edat avançada}

Tenint en compte tot el que hem dit, la Pedagogia social pot i ha de jugar un paper important en els diversos moments del cicle vital de les persones, i en l'etapa de la vellesa, aquest paper no únicament s'ha de relacionar amb l'exercici dels professionals de l'acció socioeducativa, sinó que ha de contemplar tres grans eixos (o moments) d'acció:

1. La promoció de la qualitat de vida mitjançant projectes i programes d'animació sociocultural, així com una oferta d'activitats de temps lliure de qualitat, activitats culturals, esportives, etc. En aquest eix d'acció és important promoure el benestar de la persona anciana $i$ el seu desenvolupament personal en aspectes que afecten les seves condicions generals de vida, entenent la vellesa com una etapa activa, de desenvolupament personal, de cura física i de promoció de la salut.

Són accions proactives que pretenen enfortir les relacions i les xarxes socials mitjançant una oferta sociocultural adreçada a persones que gaudeixen de salut i que viuen a casa, majoritàriament en companyia de les seves parelles, i són plenament autònomes en la seva vida quotidiana. Dins d'aquest eix hem de considerar la capacitat organitzativa i d'autogestió de la gent gran. Es tracta de reconèixer el seu saber fer i estar, el lideratge, les habilitats directives, les xarxes de contactes, el bagatge d'experiències, la capacitat d'identificar les pròpies necessitats i d'organitzar-se per mobilitzar-se. En definitiva, entenem que la Pedagogia social fonamentalment ha d'oferir espais i mitjans a les persones ancianes per tal de facilitar que aquestes puguin desenvolupar les seves iniciatives de forma autònoma i solidària.

(3) En aquest sentit, volem referir-nos a la pel-lícula canadenca Les invasions bàrbares (Denys Arcand, 2003), ja que en ella es relaten els últims dies d'un malalt en situació terminal al costat dels seus éssers més propers i estimats. I, sens dubte, la situació reflectida dista molt de la imatge tradicional d'una família, ja que qui acompanya el malalt en el seu procés de comiat i de trànsit a la mort són, en part, els seus familiars directes (en concret, un dels seus dos fills i la seva antiga esposa i mare dels seus fills), però, majoritàriament, són els amics de sempre, així com algunes de les seves antigues companyes sentimentals. En altres paraules, una xarxa de relacions i de cura molt diferent a la tradicional, però no per això menys efectiva o qualitativament menys important. 
2. El manteniment de l'autonomia personal i la prevenció de la dependència mitjançant accions socioeducatives que formen part, i complementen, els dispositius socials i assistencials que pretenen mantenir i allargar el màxim possible l'autonomia de la persona d'edat avançada. Aquests dispositius poden anar dirigits al propi individu, a la seva llar o al seu entorn familiar i relacional més immediats.

En aquest cas, pensem en persones ancianes que comencen a veure minvada la seva autonomia personal, tot apareixent o intensificant-se els problemes de salut i la pèrdua progressiva de relacions socials (dessocialització) a causa de problemes de mobilitat i de pèrdua d'amics, familiars i relacions socials. És en aquest eix en què serà clau la solidaritat de la seva comunitat.

3. Finalment, hi ha l'atenció a la persona anciana amb un grau de dependència que afecta de manera sensible la seva autonomia personal. Aquí, l'acció socioeducativa s'ha de dirigir tant al propi individu com als del seu entorn immediat afectats (principalment, els seus familiars i cuidadors), així com també als professionals o recursos assistencials implicats en la seva atenció i cura (principalment, els dels serveis d'atenció domiciliària, serveis de teleassistència, centres de dia i centres residencials).

En aquest article volem destacar el paper que la Pedagogia social pot i ha de desenvolupar en relació amb alguns dels tres aspectes abans assenyalats. Així, respecte al primer, ha de promocionar l'autogestió del temps lliure; pel que fa al segon, ha de reforçar l'autonomia personal i la prevenció de la dependència i, finalment, en el tercer eix adquireix especial rellevància enfortir l'atenció de la persona d'edat avançada dependent, mitjançant la formació i l'atenció social i educativa dels cuidadors d'aquesta persona dependent o que es troba en una fase de pèrdua progressiva de la seva autonomia personal.

A mesura que s'incrementa el grau de dependència, haurà d'aparèixer la figura del cuidador, sigui aquesta persona la seva parella, un familiar proper o algú extern a la família i que presta els seus serveis. En aquest sentit, hi ha tres grans tipus de limitacions que afecten l'autonomia de la persona gran (Tobío, Agulló, Gómez i Martín, 2010): les de mobilitat (aixecar-se, seure, caminar, etc.), les limitacions en la vida domèstica quotidiana (comprar, fer la bugada, rentar els plats, cuinar...) i les limitacions en la cura d'un mateix (pentinar-se, rentar-se, menjar, entre d'altres).

Gran part de les persones grans afronten la pèrdua progressiva d'autonomia personal en els seus propis domicilis, en el mateix entorn de sempre (els seus veïns de tota la vida, els botiguers que ja coneixen, les persones del seu carrer, el seu entorn, la seva comunitat) i en companyia dels seus familiars més directes (normalment, la seva parella, en especial en la generació actual).

D'altra banda, la literatura especialitzada distingeix clarament entre les cures formals i les atencions informals. Així, segons el sociòleg Jesús Rivera (2001), les primeres són aquelles cures i suports que es reben per part d'institucions o de serveis formalment existents a la comunitat (generalment, de caràcter social o sanitari); mentre que les atencions informals consisteixen en l'atenció no remunerada que es presta a les persones en situació de dependència per part de familiars o d'altres individus sense cap 
llaç d'unió ni d'obligació més enllà del de l'amistat o del bon veïnatge. És a dir, les cures informals són facilitades per familiars, amics o veïns que no cobren per fer-ho.

En concret, podem considerar que la cura informal presenta les característiques generals següents (Carretero, Garcés, Ródenas i Sanjosé, 2006): a) Es subministra en I'habitatge de la persona dependent; b) El cuidador informal i el receptor de cures comparteixen el mateix habitatge; c) Implica la provisió de múltiples tasques de cura centrades en l'ajuda per realitzar les activitats bàsiques i instrumentals de la vida diària; d) Les cures informals es subministren diàriament i de forma intensa; e) Els cuidadors informals solen atendre una sola persona dependent; f) La cura informal té una durada perllongada al llarg de diversos anys; $g$ ) La cura informal sol ser assumida per una única persona, el cuidador principal.

\section{Taula 3. Característiques principals dels cuidadors formals i dels informals}

Cuidadors formals

- Reben una retribució econòmica per subministrar les cures.

- Estan qualificats professionalment per a la pràctica de l'assistència (en especial professionals sanitaris i socials).

- $\quad$ Estan associats a un sistema de serveis organitzat.

- $\quad$ Proporcionen, en general, serveis de cura personal, visites d'infermeria i tasques de la llar.
Cuidadors informals

Font: Elaboració pròpia a partir de Carretero, Garcés, Ródenas i Sanjosé (2006).

S'ha de destacar l'important impacte que aquestes cures informals tenen sobre el conjunt de les persones amb algun tipus de dependència. Així, segons els resultats d'un estudi de la sociòloga $M^{a}$. Àngels Duran (2000), prop del $90 \%$ de les persones dependents són ateses per cuidadors informals, mentre que només un $11 \%$ són ateses per serveis o institucions del sector formal (serveis socials o sanitaris, atenció domiciliària, centres de dia, residències, etc.). Aquestes dades, de l'any 2000, són corroborades per l'estudi de Rogero-García (2009), segons el qual de les persones grans que necessiten cura, el $89,4 \%$ rep una atenció informal, el $14,8 \%$ és atès en serveis privats i el $8,1 \%$ en serveis públics 4 .

Aquesta realitat ens ha de fer recordar que els serveis socials i sanitaris, denominats sector formal, són un fenomen recent i que històricament i tradicionalment han estat les famílies les qui s'han responsabilitzat i ocupat de les persones dependents (ja siguin infants, malalts, persones amb diversitat funcional o persones ancianes). L'actual situació de crisi econòmica i l'elevada taxa d'atur, estan tenint incidència impulsant de nou el creixement de les xarxes informals.

(4) Cal observar que aquestes opcions no són excloents entre elles, sinó que poden complementar-se les unes amb les altres. Per exemple, la cura formal i la informal es combinen en l'11,9\% dels casos. 
És possible que aquest predomini de les cures informals en l'atenció als individus d'edat avançada en situació de dependència tingui relació amb la percepció i l'opinió que les persones grans expressen sobre quin tipus d'ajuda desitgen en cas d'una possible dependència futura. Així, segons un estudi de l'any 2007 sobre les condicions de vida de la gent gran (Abellán, del Barrio, Castejón, Esparza, Fernández-Mayoralas, Pérez, Puga, Rojo i Sancho, 2007), les persones grans no només expressen voler viure a casa, sinó que també manifesten clarament la seva preferència en ser ateses, en cas de necessitat, en el seu propi domicili $(77,3 \%)$ o, com a segona opció, i a una considerable distància de la primera, conviure amb els seus fills (33\%). Per contra, les alternatives de caràcter institucional troben un feble grau d'acceptació. Així, l'opció dels centres de dia només troba un $13 \%$ d'acceptació, mentre que en el cas de les residències aquest percentatge és només del 10,2\%.

D'altra banda, és interessant observar una altra dada aportada per aquest mateix estudi: més de la meitat de les persones grans consideren que avui dia els fills cuiden pitjor als seus pares que no les generacions anteriors, mentre que el $27,8 \%$ creu que ho fan de forma similar; i només el 7\% pensa que els fills d'avui dia han millorat en la cura dels seus pares.

En el moment de valorar com un indicador de la qualitat de vida de les persones grans que aquestes puguin continuar vivint en el seu propi domicili i en el seu entorn, hem de tenir en compte que una part important d'aquest collectiu porta molts anys residint en el mateix habitatge $i$ en el mateix barri. Per exemple, en el cas de la ciutat de Barcelona, el $56,3 \%$ de les persones de més de 65 anys fa entre 26 i 50 anys que viuen en el mateix habitatge, mentre que un $12,8 \%$ porta en aquest més de 50 anys (Ajuntament de Barcelona, 2009). D'altra banda, si se'ls pregunta si tenen intenció de canviar de residència durant els propers cinc anys, un $96 \%$ dels de més de 65 anys respon que no. Pensem que aquesta opinió no només s'ha d'atribuir a la situació econòmica o a les incerteses davant el futur, sinó que també s'ha de relacionar amb la valoració positiva que tenen sobre el seu habitatge i el seu barri, ja que el $66,6 \%$ de les persones de més de 65 anys manifesta que la seva vivenda actual és el lloc preferit per viure, mentre que sols el 13,9\% manifesta que canviaria de pis però no de barri ${ }^{5}$.

En relació amb el paràgraf anterior, també hem de tenir en compte l'impacte de l'antiguitat dels habitatges en què viuen les persones de més de 65 anys, ja que aquest collectiu presenta un notable nivell de sedentarisme que implica que molts d'ells portin vivint en el mateix domicili molts anys. En el cas de la ciutat de Barcelona, el 10,2\% de les persones majors de 65 anys viu en habitatges construïts abans de l'any 1900, el $40,2 \%$ en vivendes construides entre els anys 1900 i 1960 i només el 7,4 \% en edificacions construides amb posterioritat a l'any 1980 (Ajuntament de Barcelona, 2009). Aquestes xifres tenen una relació directa amb les condicions de vida quotidiana de les persones grans, ja que l'habitabilitat i l'equipament d'aquests habitatges es

(5) Pensem que aquestes xifres adquireixen una especial rellevància en el moment que les comparem amb les de les persones menors de 65 anys, ja que s'observen notables diferències entre aquests dos col.lectius. Així, en el cas dels que no tenen intenció de canviar d'habitatge durant els propers cinc anys, els percentatges són del 68,4\% en el cas dels menors de 65 anys i del $96 \%$ en el cas dels majors de 65 anys; mentre que respecte al lloc preferit per viure, el 32,9\% dels menors de 65 anys i el $66,6 \%$ dels majors de 65 anys manifesten que és el seu habitatge actual $i$, en el cas del barri on viuen, els percentatges de satisfacció representen el 57,9\% dels menors de 65 anys i el 80,5\% dels majors de 65 anys (Ajuntament de Barcelona, 2009). 
veuen afectats per l'antiguitat. Així, quelcom tan bàsic per a l'autonomia de persones amb mobilitat reduïda com és l'ascensor, només es troba en el 63,7\% dels habitatges de la ciutat de Barcelona en què viuen persones més grans de 65 anys.

Aquestes dades cal contrastar-les amb les conclusions de dos estudis posteriors de I'Ajuntament de Barcelona (2013 i 2016), ja que la crisi econòmica dels darrers anys ha provocat una millora substancial de les condicions residencials de les persones grans en relació amb la resta de població de la ciutat. Possiblement no es tracta que les seves condicions residencials hagin millorat, sinó, més aviat, que les de la resta de la població han empitjorat. Bàsicament, pel que fa al règim de tinença i les condicions de l'habitatge principal, s'observen quatre característiques importants (Ajuntament de Barcelona, 2013 i 2016):

a) En les darreres dècades la població gran de la ciutat de Barcelona ha incrementat la seva condició de propietària de l'habitatge respecte a la resta de la població, si bé a partir de l'any 2006 aquesta xifra es manté força estable al voltant del $68-70 \%$.

b) Una part important de les persones de més de 65 anys que viuen en habitatges de lloguer ho fan sota contractes vinculats a la legislació antiga d'arrendaments. Segons dades de l'any 2011, el 21,6\% de la població de 65 anys i més viu en habitatges de lloguer i, d'aquests, el $66,7 \%$ ho fa en vivendes de renda antiga. Mentre que el percentatge de persones de 65 i més anys que viu en habitatges de lloguer és sensiblement inferior al del conjunt de la població, el percentatge que ho fa en vivendes de renda antiga és molt superior.

c) Les condicions residencials de la població gran són pitjors quan viuen en habitatges de lloguer, ja que acostumen a ser antics i amb contractes de renda antiga $\mathrm{i}$, per tant, amb poques inversions de manteniment per part dels propietaris.

d) L'impacte de la despesa d'habitatge en la renda familiar de la població de 65 anys i més és menor en relació amb la resta de població. Aquest fet pot explicarse per dues de les característiques abans mencionades: l'elevat percentatge $d^{\prime}$ 'habitatges en propietat $i$, en el cas dels lloguers, l'alt percentatge de vivendes de renda antiga.

\section{Algunes reflexions sobre la cura i la formació dels cuidadors informals}

Tal com dèiem abans, entre l'autonomia personal i la possible dependència de la persona anciana hi ha una fase intermèdia en la qual els dispositius socials i assistencials pretenen mantenir i allargar el màxim possible l'autonomia d'aquesta. Pensem que en el moment en què es produeixen aquests canvis en la persona gran, i en els quals es planteja la necessitat d'incrementar l'atenció i la cura, el paper de la Pedagogia social és important. En altres paraules, aquesta disciplina no només juga una destacada funció en el moment inicial i final d'aquest procés -és a dir, en el disseny i desenvolupament de projectes i programes socioculturals mentre les persones grans són plenament autònomes o d'accions socioeducatives en dispositius assistencials quan la persona anciana requereix d'una atenció específica i especialitzada-, sinó també en les fases intermè- 
dies, i per això focalitzarem la nostra atenció en la funció que pot jugar en la formació i atenció educativa dels cuidadors.

Normalment, els cuidadors informals o no professionals solen presentar un vincle familiar amb la persona anciana dependent -en la major part dels casos, són la seva parella, generalment les dones, o bé els seus fills o filles (també en aquest cas la cura presenta un notable biaix femení)-. Però en alguns casos aquests cuidadors poden formar part de les xarxes d'amistat, veïnatge o voluntariat.

Podem afirmar que la majoria de persones grans són ateses per algun familiar de primer grau, bo i destacant factors de consanguinitat, parentiu i matrilinealitat (Tobío et al., 2010). És a dir, la solidaritat de la cura es fonamenta en la família i únicament un petit percentatge de persones grans són ateses per agents externs a aquesta.

Per tot això, hem de tenir en compte que l'atenció i la cura de persones grans en situació de dependència presenta un impacte notable en la vida personal, familiar, social i professional dels seus cuidadors informals (principalment familiars). Entre aquestes possibles conseqüències (Agulló, 2002), podem destacar les que afecten de forma negativa les condicions físiques i de salut (cansament, estrès, alteracions del son, dolors, increment en el consum de fàrmacs, etc.), les condicions socioeconòmiques (augment de les despeses, inseguretat econòmica, reducció de la jornada laboral, absentisme laboral, menys possibilitats de promoció professional, pèrdua de posició social, etc.), les psicològiques i psicosocials (sensació de solitud, de pèrdua de llibertat i de domini per part de la persona dependent, pessimisme, desil.lusió, síndrome del cuidador, etc.) i les relacionals i familiars (conflictes intergeneracionals, disminució de la vida social i del temps lliure, maltractaments mutus, manca d'espai físic, mental i social, etc.).

En aquest sentit, i d'acord amb les dades proporcionades pel Libro blanco de la atención a las personas con dependencia en España (IMSERSO, 2005), els cuidadors informals de persones dependents manifesten haver patit conseqüències negatives derivades d'aquestes cures en aspectes relatius a la salut (55,6\%), en aspectes professionals i econòmics $(61,0 \%)$ i en aspectes d'oci, temps Iliure i vida familiar $(80,2 \%)$.

Així, en relació amb les conseqüències per a la salut física i psicològica, el 32,7\% dels cuidadors informals reconeix sentir-se cansat, el $27,5 \%$ reconeix que la seva salut s'ha deteriorat i el $18,1 \%$ que es troba deprimit. Pel que fa a les conseqüències professionals i econòmiques, el $26,4 \%$ dels cuidadors reconeix no poder plantejar-se treballar fora de casa, el 15,1\% té problemes econòmics, I'11,7\% ha hagut de deixar de treballar, l'11,2\% ha hagut de reduir la seva jornada laboral, el 10,7\% té problemes per complir l'horari de treball i el 7,2\% reconeix que la seva vida laboral s'ha ressentit. Finalment, pel que fa a les conseqüències d'oci, temps Iliure i vida familiar, el 61,8\% reconeix haver reduït el seu temps d'oci, el $38,0 \%$ no pot anar de vacances, el 31,8\% no disposa de temps per freqüentar les seves amistats, el $27,2 \%$ no té temps per tenir cura de si mateix, el $17,4 \%$ no disposa de temps per tenir cura d'altres persones que no siguin la que es troba en situació de dependència i el 7,0\% reconeix tenir conflictes amb la seva parella (IMSERSO, 2005).

Aquest impacte en la vida personal, familiar, social i professional dels cuidadors informals es complementa amb les necessitats o els problemes a què s'enfronta el cuidador familiar i que assenyala la doctora Àngels Tresserra (2008): a) desajust entre el 
temps que els dedica el cuidador familiar i les necessitats de la persona en situació de dependència; b) gran desgast físic i mental; c) necessitat d'abandonar el món laboral; d) reducció d'hores de temps lliure; e) reducció de relacions familiars i socials; f) dedicació exclusiva a la persona en situació de dependència; $g$ ) autoabandonament físic i anímic; h) aïllament social; i) falta de reemplaçament; j) manca de recursos econòmics.

Entre les necessitats dels cuidadors informals, el professor Feliciano Villar (2009) destaca les següents: informació adequada sobre el procés que afecta la persona dependent; orientació sobre com fer front a les mancances progressives i a les crisis que pot generar la dependència; saber organitzar-se; valorar els recursos disponibles (financers, temporals, físics, socials); conèixer com obtenir ajuda externa (amics, associacions, voluntariat, institucions); mantenir les activitats habituals; saber com tenir cura de l'altre i d'un mateix; planificar el futur i tenir la capacitat de recuperar el normal funcionament personal i familiar quan la persona gran dependent desapareix (sigui per requeriment de cures formals, sigui per defunció). Per la seva banda, Agulló (2002) assenyala que el collectiu de cuidadors presenta un conjunt de necessitats específiques, tot requerint suport físic, acompanyament psicològic, suport social i, finalment, ajuda econòmica.

Per tot això, la formació dels cuidadors és clau en molts aspectes. Per exemple, la capacitat predictiva de les necessitats de la persona dependent suposa una millora de la seva atenció, al mateix temps que afavoreix el benestar emocional del cuidador, ja que aquest, en tant que se sent capaç d'anticipar-se a les situacions, es reafirma en l'adequat exercici de les cures. Els coneixements relacionats amb una dieta saludable, amb exercicis afavoridors de la mobilitat, amb la cura de la pell, amb l'ergonomia, amb els indicadors sanitaris o amb les cures simples, permeten una millor atenció i disminueixen la necessitat de suport extern. El tenir cura d'una persona en situació de dependència acostuma a provocar la desatenció de les pròpies necessitats. Així doncs, un reforç positiu de l'autocura com una manera responsable de tenir cura de l'altre esdevé una necessitat rellevant. El desgast emocional de l'atenció d'una persona dependent necessita espais de paraula per compartir les dificultats, desproblematitzar el dia a dia, relativitzar els conflictes, com a manera de mantenir una forta autoestima, iniciativa i equilibri personal.

A la vista del que diem, i des d'una perspectiva socioeducativa, podem de destacar tres aspectes:

1. El treball educatiu amb la persona anciana amb l'objectiu que aquesta entengui què li succeeix i s'enfronti de forma proactiva, positiva i constructiva al progressiu estat de dependència, així com que tingui coneixement de tot allò que pot beneficiar la seva autonomia i mantenir la seva qualitat de vida, tant des de la perspectiva de dispositius assistencials existents, com d'adaptació psicològica i social o hàbits i comportaments de vida quotidiana.

2. El treball educatiu amb els familiars que conviuen amb la persona gran o que mantenen una relació freqüent amb ella (parella, fills i filles, germanes o germans, néts...). En aquest sentit, és important que aquests individus que conviuen i tenen cura, o bé que només es relacionen, però de manera intensa $\mathrm{i}$ freqüent, amb la persona anciana, coneguin i entenguin què és el que li està passant a aquesta, que aprenguin com actuar tant des de la perspectiva relacional com des de les accions que es poden desenvolupar per afavorir 
l'autonomia i, en especial, que siguin capaços de ressituar-se a nivell emocional, així com en els rols i les funcions assignats a cada membre de la família que en aquesta fase canvien intensament. També el treball des de la perspectiva comunitària, ja que cal cercar xarxes de suport en el propi entorn que millorin la qualitat de vida de la persona dependent i del cuidador.

3. La formació dels cuidadors professionals.

Pel que fa al segon punt, el treball educatiu amb els familiars que conviuen amb la persona gran o que mantenen una relació freqüent amb ella, podem afirmar, d'acord amb Villar (2009), que els programes formatius dirigits als cuidadors informals aborden dos grans eixos d'acció: a) La formació sobre com tenir cura de la persona gran dependent, ja sigui en general o dirigida a situacions que poden generar dificultats específiques (incontinència, mobilitat, agressivitat, etc.); b) La formació sobre com els cuidadors han de tenir cura de si mateixos, el qual repercutirà, a mitjà i llarg termini, en la salut i el benestar del cuidador i en la qualitat de les cures que aquest presta a la persona en situació de dependència (i, per tant, en el benestar d'aquesta).

Pel que fa al primer apartat, la formació dirigida a tenir cura de la persona gran dependent, es destaquen quatre línies formatives: la capacitació per afavorir l'autonomia i aprendre a establir límits; la promoció de l'autoestima del cuidador; l'aprenentatge de com adaptar l'entorn físic domèstic i de vida quotidiana i la difusió dels diferents recursos d'ajuda i de suport dels quals es pot disposar.

En relació amb el segon apartat, la formació centrada en com els cuidadors han de tenir cura de si mateixos, hi ha tres línies formatives o de reflexió: aprendre a solucionar problemes i planificar el futur; identificar i controlar les emocions i tenir cura de la pròpia salut.

En aquesta direcció, hem d'explicitar la formació ètica dels cuidadors. Si entenem l'ètica com la capacitat d'entendre per què hem d'actuar d'una determinada manera, és imprescindible dotar el cuidador d'aquesta capacitat. En el seu dia a dia, aquest individu haurà d'afrontar moltes decisions relacionades amb el benestar de la persona dependent. Així doncs, ha de contraposar de manera contínua els seus propis valors, les creences, els costums i les maneres de pensar i d'actuar amb els de la persona a qui atén. Saber-se cuidar implica, com defensa Joan Canimas (2010), saber analitzar la presa de decisions i adoptar una ètica dialògica que es centra en la capacitat de dialogar amb els altres per tal de trobar la millor solució tenint en compte la seva viabilitat i la recerca del bé comú.

L'ètica és, doncs, la capacitat d'interrogar-se del perquè hem de tenir cura de l'altre, del perquè hem de fer les coses d'una manera o d'una altra. Aquesta capacitat és clau en els cuidadors, ja que els facilita tot un seguit d'arguments que justifiquen les seves accions i les seves decisions.

Com hem dit, entre cuidador i persona dependent es donen vincles emocionals i afectius. Edgar Morin (2006) afirma que en el sentiment de l'amor és necessari mantenir la vigília de la raó. Certament, cal reconèixer l'amor en les accions dels cuidadors i el desig legítim de satisfer a l'altre, però al mateix temps haurem d'ajudar-lo a atendre a la raó com a límit a l'amor. El cuidador ha de poder objectivar els seus dilemes i construir les seves raons en l'atenció física i emocional del dependent. 
Tenir cura és un fet complex. Així doncs, hem de reprendre el concepte de l'ètica de la complexitat de Joan Canimas (2010 i 2011) i entendre que les decisions es prenen en un moment històric concret, en una situació geogràfica específica, tot partint de les pròpies experiències i reconeixent els nostres sentiments o les característiques socioculturals del nostre entorn. Les nostres decisions no són lliures, estan condicionades pel sistema de valors, creences i formes de fer de la nostra comunitat i del context sociocultural i històric. Així doncs, no es tracta de dotar al cuidador de la raó o de distingir entre el bé i el mal, sinó de dotar-lo de la capacitat d'analitzar la complexitat de les situacions a les quals s'enfronta i saber escoltar, atendre, empatitzar amb el seu entorn per tal de trobar una solució des de la igualtat, des del reconeixement d'un mateix i dels altres. Hem de descarregar-lo de la responsabilitat de triar la millor solució, a favor de la capacitat de poder resoldre una situació donada en un moment concret, entenent que en un altre moment i en un altre context l'elecció podria ser diferent. És a dir, alliberar-lo de les eleccions transcendentals en favor de les que són possibles i viables.

També hem de facilitar que el cuidador tingui la capacitat de saber-se explicar, ja que no només cal saber prendre una decisió de manera segura i argumentada, sinó que també és necessari saber convèncer els altres que hem pres la millor elecció. Així, doncs, el cuidador ha de saber empatitzar per entendre les resistències, els temors, les pors, i les desconfiances dels altres pel que fa a la seva presa de decisions. És el que Canimas anomena la compassió com l'exercici d'acompanyar a l'altre en el procés d'acceptar la decisió presa.

Una de les claus de la Pedagogia Social és l'acompanyament educatiu de l'altre. El cuidador no només ha de saber tenir cura de la persona dependent, sinó que ha de saber-la reconèixer com a subjecte autònom i ajudar-la a entendre què li està passant, ha de trobar fórmules que facilitin la qualitat de vida, ha de tenir la capacitat de donar resposta a les noves necessitats de la forma més àgil possible i amb el menor impacte per a tothom i ha de poder treure el màxim partit dels recursos que estan disponibles en l'entorn més proper. La Pedagogia social recorda al cuidador que no està sol en aquest procés, sinó que té a veure amb un benestar comú, amb la sostenibilitat d'una comunitat i que, per tant, pot i ha de recolzar-se en aquesta comunitat.

La dependència ens confronta diàriament i a cada moment amb la incapacitat, amb la dificultat, amb la pèrdua, amb les limitacions. La naturalesa humana està preparada per afrontar reptes, per l'autosuperació, per a la millora contínua. Però en la nostra educació i en el nostre creixement personal no estem preparats per a les pèrdues, els fracassos, les ruptures, la malaltia o la mort. La Pedagogia social haurà d'acompanyar al cuidador i a la persona dependent en aquest procés degeneratiu en què per endavant sabem que trobarem la gran dependència i/o la mort al final del camí. Un cop més, l'exercici de la paraula pot ajudar a construir l'acceptació de la nova realitat, a afrontar un nou tipus de repte que no es basa en la superació, sinó en l'acceptació de la pèrdua. Acompanyar implicarà reconèixer l'altre en la seva capacitat d'obrar, de decidir, de pensar. Implicarà acceptar el dolor, la tristesa, el desànim, la por. Acompanyar significarà mantenir una distància suficient (o potser hauríem de parlar de proximitat òptima) per transformar positivament les situacions del dia a dia, per trobar petites satisfaccions, reptes d'autosuperació possibles, sense enganyar ni donar falses expectatives o prometre millores falses o impossibles. El cuidador ha d'acompanyar a l'altre ajudant-lo a posar paraules, a assumir les pèrdues des de l'esperança de la qualitat de vida, del 
benestar emocional, del saber-se estimat i cuidat, així com del respecte mutu, de la confiança i del reconeixement.

\section{A tall de conclusió}

Reivindiquem la necessitat d'intervenir educativament des de la mirada de la Pedagogia social en aquells moments en què la persona gran i els seus familiars es veuen sotmesos a un profund canvi en les seves vides i en els seus sistemes de relació, cura i suport mutu a causa de la progressiva dependència de la persona gran. Aquesta atenció socioeducativa, dirigida tant a la persona gran com als seus familiars i cuidadors, ha de contemplar quatre aspectes abans assenyalats: conèixer els processos que afecten la pèrdua d'autonomia de la persona gran, fer visible com aquests processos impacten en el desenvolupament de la vida quotidiana, conèixer estratègies d'acció que permetin minorar el seu impacte i, finalment, assimilar la necessària recol-locació de rols i funcions en el si de l'estructura familiar (saber ajudar i cuidar, però també saber acceptar l'ajuda i la cura).

Finalment, volem assenyalar un aspecte que pensem pot ser rellevant en molts casos: el cuidador familiar pot presentar una diferència qualitativa important respecte al cuidador professional que no només té a veure amb la formació i la qualificació que aquest últim té per a l'execució de les seves tasques. És possible, per no dir segur, que el cuidador familiar presenti vincles més intensos amb la persona anciana, desenvolupi una major implicació i, conseqüentment, mantingui una menor distància (o si voleu una excessiva i tòxica proximitat) amb aquesta situació i les necessitats associades. És per això que considerem necessari que aquest cuidador informal aprengui a protegir-se i a prendre distància, que sigui capaç d'objectivar les situacions que ha d'afrontar o que prengui consciència de la necessitat de cuidar-se i, per tant, que aprengui o sàpiga tenir cura de si mateix. En definitiva, la Pedagogia social ha d'aportar elements que permetin tenir cura del cuidador i que aquest prengui consciència, especialment si no és un professional, de la importància del saber-se cuidar a un mateix i que sàpiga com fer-ho.

Remarquem que és molt important l'autocura del cuidador, ja que cuidar-se a un mateix és la millor manera de tenir cura de la família i de la persona en situació de dependència que es té a càrrec. Per autocura hem d'entendre totes aquelles actituds i accions que adopta el cuidador familiar que van encaminades a valorar-se a un mateix, estimar-se i cuidar-se. Són, en definitiva, accions que tenen com a objecte mantenir i millorar la pròpia salut física i mental.

La qualitat de la cura no només dependrà de la qualitat de vida de la persona gran, sinó que també dependrà de la del familiar cuidador. És a dir, aquest no només ha de saber com tenir cura de la persona gran, sinó que també ha de saber cuidar-se a si mateix. I, sense cap dubte, res ni ningú ha preparat ni format a aquests individus per afrontar unes situacions de necessitat i dependència que no només afecten els seus éssers estimats, sinó que també alteren les seves pautes i formes de vida quotidiana, familiar i social.

És important tenir en compte que les intervencions socioeducatives sobre la conducta i les habilitats del cuidador informal a l'hora d'interactuar amb la persona anciana dependent poden prolongar la capacitat del cuidador per proporcionar cura domiciliària i assegurar la qualitat de vida tant del cuidador com de la persona cuidada. En altres 
paraules, la inversió en programes de formació i de suport als cuidadors informals no només implica una millora de la qualitat de vida del cuidador i de la persona en situació de dependència, sinó que també representa una excel·lent inversió (humana, social i, també, econòmica) en el sentit de perllongar en el temps la capacitat del cuidador i, per tant, posposar la necessitat de cures formals. És aquest, sens dubte, un important repte per a la Pedagogia social.

\section{Referències}

Abellán, A.; del Barrio, E.; Castejón, P.; Esparza, C.; Fernández-Mayoralas, G.; Pérez, L.; Puga, M. D.; Rojo, F. i Sancho, M. (2007) A propósito de las condiciones de vida de las personas mayores. Madrid, Imserso.

Agulló, M. S. (2002) Mujeres, cuidados y bienestar social: el apoyo informal a la infancia y a la vejez. Madrid, Instituto de la Mujer.

Ajuntament de Barcelona (2009) Condicions de vida i hàbits de la gent gran a la ciutat de Barcelona. Barcelona, Àrea d'Acció Social i Ciutadania, Ajuntament de Barcelona.

Ajuntament de Barcelona (2013) Les condicions de vida de les persones grans a la ciutat de Barcelona. Barcelona, Àrea de Qualitat de Vida, Igualtat i Esports, Ajuntament de Barcelona.

Ajuntament de Barcelona (2016) Les condicions de vida de les persones grans a Barcelona $i$ la resposta de la ciutat. Barcelona, Àrea de Qualitat de Vida, Igualtat i Esports, Ajuntament de Barcelona.

Campo, M. J. (2000) Apoyo informal a las personas mayores y el papel de la mujer cuidadora. Madrid, Centro de Investigaciones Sociológicas.

Canimas, J. (2010) Practica l'ètica dels Serveis socials. Girona, Campus Arnau d'Escala.

Canimas, J. (2011) L'ètica aplicada als Serveis socials. Barcelona, Universitat Oberta de Catalunya.

Carretero, S.; Garcés, J.; Ródenas, F. i Sanjosé, V. (2006) La sobrecarga de las cuidadoras de personas dependientes. Análisis y propuestas de intervención psicosocial. València, Tirant lo Blanch.

Duque, J. M. i Mateo, A. (Coord.) (2008) La participación social de las personas mayores. Madrid, Imserso.

Duran, M. A. (2000) Los costes invisibles de la enfermedad. Madrid, Fundación BBVA.

Fuentes, E. i Solé, J. (2012) «Las condiciones de vida de las personas mayores y los servicios sociales municipales». Pedagogía Social. Revista Interuniversitaria (Sociedad Ibérica de Pedagogía Social), 19, p. 83-98.

Fundación Instituto Gerontológico Matia (2009) Las dimensiones subjetivas del envejecimiento. Madrid, Imserso.

Hidalgo, A. (Coord.) (2010) Trabajo social con enfermos de Alzhéimer y sus familias: Reflexiones y sugerencias. Madrid, UNED.

IMSERSO (2005) Libro blanco de la atención a las personas con dependencia en España. Madrid, IMSERSO.

Lisbona, A.; Nomen, L. i Pliego, M. (2009) SOS... soy dependiente: Estrategias para mejorar la calidad de vida. Madrid, Pirámide. 
Morin, E. (2006) El método 6. Ética. Madrid, Cátedra.

Rivera, J. (2001) Redes familiares en el cuidado del anciano con demencia: análisis evolutivo de un estudio poblacional. Madrid, Consejo Económico y Social de España.

Rogero-García, J. (2009) «Distribución en España del cuidado formal e informal a las personas de 65 y más años en situación de dependencia». Revista Española de Salud Pública (Ministerio de Sanidad Servicios Sociales e Igualdad), 83, p. 393-405.

Rojo-Pérez, F. i Fernández-Mayoralas, G. (Eds.) (2011) Calidad de vida y envejecimiento: La visión de los mayores sobre sus condiciones de vida. Bilbao, Fundación BBVA.

Tobío, C.; Agulló, M. S.; Gómez, M. V. i Martín, M. T. (2010) La cura de les persones: Un repte per al segle XXI. Barcelona, Fundació "la Caixa".

Tresserra, A. (dir.) (2008) Un cuidador, dues vides. Programa d'atenció a la dependència, suport al cuidador familiar. Barcelona, Fundació "la Caixa".

Villar, F. (2009) Discapacidad, dependencia y autonomía en la vejez. Barcelona, Aresta. 


\section{Pedagogía social, vejez y autonomía personal}

Resumen: Actualmente existen cambios demográficos, socioculturales y económicos que transforman las relaciones personales y sociales, así como las estructuras familiares y, en consecuencia, las formas tradicionales de cuidado de las personas ancianas, tanto en lo referente a la promoción de su calidad de vida como al mantenimiento de su autonomía personal y de su cuidado en las situaciones de dependencia. Dichos procesos no solo afectan los valores y los patrones de vida de las personas mayores, sino también a sus posibles cuidadores, que en su mayoría son familiares directos. La Pedagogía social desempeña un papel en los diversos momentos del ciclo vital y en la etapa de la ancianidad; este papel no deberá relacionarse únicamente con el ejercicio de los profesionales de la acción socioeducativa, sino que también deberá tener en cuenta la vida y las necesidades de las propias personas de edad avanzada y de sus posibles cuidadores informales. Primero, favoreciendo la calidad de vida y la autonomía de los individuos ancianos; después, previniendo y retardando la dependencia; $y$, finalmente, acompañando a sus cuidadores.

Palabras clave: Vejez, pedagogía social, calidad de vida, bienestar, autonomía personal, dependencia.

\section{Pédagogie sociale, vieillesse et autonomie personnelle}

Résumé : Les changements démographiques, socioculturels et économiques transforment les relations personnelles et sociales, les structures familiales et les modes traditionnels de prise en charge des personnes âgées, tant pour la promotion de leur qualité de vie comment pour préserver et promouvoir leur autonomie personnelle. Ces processus de change sont importants parce qu'ils affectent les valeurs et les modes de vie de ces personnes, ainsi que sur leurs aidants potentiels, habituellement des parents directs. La pédagogie sociale joue un rôle aux différentes étapes de la vie, ainsi dans la vieillesse, cela doit non seulement être lié à l'action des professionnels de l'attention socio-éducative, sinon aussi sur les personnes âgées et leurs aidants naturels. La pédagogie sociale devrait promouvoir la qualité de vie et l'autonomie des personnes tout au long de leur processus de vieillissement.

Mots clés : Vieillesse, pédagogie sociale, qualité de vie, bien-être, autonomie personnelle, dépendance.

\section{Social pedagogy, old age and personal autonomy}

Abstract: In contemporary Western society take place demographic, sociocultural, economic and psychosocial changes that transform personal and social relationships as well as family structures and, as a result, traditional forms of care of the elderly, both in relation to the promotion of quality of life, as the maintenance of their personal autonomy and its care when appears or increases their dependency status. These processes not only affect the values and patterns of life of the elderly, but they affect directly potential caregivers, who in their vast majority are immediate family members. Social pedagogy must play an important role in the various moments of the life cycle of the people, and in the stage of old age, this role should not only relate to the exercise of the socioeducational action professionals, but they must take into account the needs of the elderly people and their possible informal caregivers. Social pedagogy should promote quality of life and autonomy of people at different stages of their aging process: while they are fully autonomous, when they begin to lose autonomy and, finally, when they are dependent and need support from caregivers.

Keywords: Old age, social pedagogy, quality of life, well-being, personal autonomy, dependency. 